\title{
Reflections on Status Quo of TCM Health Care Services and Its Legal Problems
}

\author{
From the Perspective of Non-medical Institutions
}

\author{
Yuqing Zhang \\ College of Humanities \\ Hubei University of Chinese Medicine \\ Wuhan, China 430065
}

\author{
Ziwei Li \\ Law School \\ Huazhong University of Science and Technology \\ Wuhan, China 430070
}

\begin{abstract}
With the continuous development of economic development and people's living standards, the people's attention to their own health is getting higher and higher, and the demand for health care markets is growing. Accordingly, there is a surge of TCM health care in our country. However, the development of TCM health care service industry is not mature, especially the development and operation of non-medical organizations. There are many problems, such as imperfect health care service system, imperfect market regulation and access system, and lack of supervision. From the perspective of non-medical institutions, this paper conducts research and analysis on the status quo of the development of TCM health care industry and existing legal issues, and proposes targeted solutions, with a view to providing new ideas for promoting the rapid development of TCM health care service industry in China.
\end{abstract}

Keywords-Chinese medicine; health care; current situation; legal thinking

\section{INTRODUCTION}

"The best measure is to treat the disease before it happens." The Chinese nation has always attached importance to health care and health care. After thousands of years of development, TCM health care science has formed a profound theoretical foundation and is widely used in practice. It represents the wisdom of the Chinese nation and a cultural treasure. The proportion of traditional Chinese medicine health care in people's lives is increasing, and it has also become a new economic growth point and strategic industry. Summarizing the current development status of TCM health care services in China and analyzing the existing problems is of great significance to establish and improve the TCM health care service system construction in China and advance the "Healthy China" strategy.

\section{DEFINITION AND DEVELOPMENT STATUS OF TCM HEALTH CARE SERVICES}

\section{A. Definition of TCM Health Care Services}

According to the "Basic Standards for TCM Health Care Service Organizations" (Trial), TCM health care refers to the use of the theories, concepts, and methods and methods of TCM health care to carry out service activities such as maintaining the body, reducing disease, enhancing health, and extending longevity."

\section{B. Development Status of TCM Health Care Services in Non- Medical Institutions}

According to the relevant data, the total sales volume of China's health care industry has reached 650 billion yuan, of which private capital takes up more than $90 \%$.There are about 12,000 domestic manufacturers of health food products, more than 100,000 sales companies, more than 1.4 million service companies, and more than 50 million employees. Non-medical institutions' TCM health care services are mainly in the form of rehabilitation hospitals, health clubs, acupuncture and massage halls, and dietary restaurants. They mainly provide massage services of TCM, foot massage of TCM, and medicinal dishes of TCM.

\section{REORGANIZATION OF RELATED LAWS AND} REGULATIONS ON TCM HEALTH CARE SERVICES (2014-2017)

\section{A. "Reply for Supervision of Traditional Chinese Medicine in the Special Action Against Illegal Practice" (Hereinafter Refer to as "Reply")}

For the first time, the State Administration of traditional Chinese medicine and the State Health Planning Commission separate some Chinese medical diagnosis and treatment techniques from health care technology, and strictly stipulate technical projects that non medical institutions may not carry out in the "Reply".

\section{B. "Temporary Provisions about TCM Physicians Providing Health Consultation and Conditioning Services in Health Care Institutions" (2016)}

The State Administration of Traditional Chinese Medicine in this provision clarifies that "TCM physician" can engage in five aspects of health assessment, health consultation, health care, establishment of medical records, and skills training in TCM health care. At the same time, this provision also clarifies the three tasks that Chinese medicine practitioners cannot engage in. 


\section{Guiding Opinions on Promoting the Development of TCM Health Care Services (2016)}

The State Administration of Traditional Chinese Medicine pointed out in this opinion that "by 2020, we will basically establish a TCM health care service system that is developed in collaboration with non-medical TCM health care institutions and medical and health institutions." Meanwhile, the opinion put forward that "Encourage social forces to hold TCM health care organizations" and "Cultivate a group of well-known TCM health care groups or chain institutions of good skills and reputations."

\section{D. "Chinese Medicine Law" (2017)}

The "Chinese Medicine Law" states that "to carry out Chinese medicine services should be based on the theory of Chinese medicine, use Chinese medicine techniques, and comply with the basic requirements for Chinese medicine services formulated by the competent department of State Council in charge of Chinese medicine." The "Chinese medicine service" here includes TCM health care services.

\section{LEGAl Problems IN TCM HeAlth CARE SERVICES}

\section{A. Imperfect Market Access System and Chaos of Order}

According to the current laws and regulations, the establishment of a TCM health care service agency only requires the approval of the industrial and commercial administrative department to obtain a business license. From the perspective of industrial and commercial registration access conditions, manipulation, massage, scraping, and weight loss are all can be included in the scope of the license as long as the words "medical treatment" and "treatment" are not explicitly proposed. The industry's pre-approval is only a health permit, and it is not necessary. The pedicure clubs and massage clubs that without public baths and bathing facilities are not included in the 28 categories listed in Article 2 of the Regulations on the Management of Public Places and therefore they do not need to hold a Health Permit. However, the health conditions of some TCM health service organizations are worrying. For example, the glass jars used for cupping will be cupped without any disinfection and are then used again for other customers. If a customer has a skin disease or other infectious disease, it will be transmitted to others and damage the health of the customer.

Although the "Chinese Medicine Law" that has already been implemented stipulates that "the competent department of Chinese medicine of the State Council shall formulate the norms and standards for the health care services of TCM."However, the formulation of relevant supporting regulations and the introduction of TCM health care service norms and standards still need a process. Therefore, judging from the current situation, due to the low market access conditions, the enterprises entering the market have been being affected by the bad. The market order is very confusing and there are some illegal acts. In 2016, 2725 complaints from consumer health care services were accepted by the National Consumer Association, 2209 more than in 2015, and there was a significant increase in health care complaints.

\section{B. The Qualifications of the Employees Are Worrying and the Licenses Are Confusing}

"According to the "Blue Book on the Development of China's Health Service Industry" published by the China Health Care Association in 2012, the total number of health care service enterprises in China has reached more than 1.4 million, and employs more than 37 million people." while the total number of Chinese and Western medical practitioners and practicing assistant physicians is 3.6 million. The names of these practitioners of TCM health care are varied, including "health care practitioners", "dietitian", and "health care instructors". Most of them are characterized by low level of education, young age, non-standard service, and low technical level. Although all of them claim to have learned Chinese medicine health knowledge, very few of them graduate from a Chinese medicine college. For example, some health care institutions do not even have one graduate of a Chinese medicine college. After internal training for 3 months, they can take up a job to provide massage services. As Chinese medicine is extensive and profound, in terms of massage, "doctors engaged in therapeutic massage often take several years or even lifetimes of medical professional learning and long-term practice to achieve good results."

At present, in addition to the Ministry of Human Resources and Social Security, China Academy of Chinese Medical Sciences and some societies, associations, training schools, etc. also have training classes for health care. These institutions and associations themselves have poor qualifications. How can they guarantee the qualification level of trainees? In addition, the conditions for recruiting trainees in training institutions are also uneven. Some institutions only require trainees to "have the relevant junior college degree, and work in relevant industries for more than 1 year continuously", and some may even ask for high school or secondary school degree with continuous 2 years of relevant working experiences.

Although the "Basic Standards" stipulate that "workers engaged in TCM health care services should have corresponding qualification certificates issued by relevant departments of the state and employees who have graduated from TCM colleges and universities need to go through training organized by or recognized by the health administrative department at or above the county level and ensure that the appraisal has reached a passable level."The provisions are general and vague. What is the "relevant departments of the state"? What "the organization that organized by or recognized by the Ministry of Health Administration at county level or above" are specifically refer to? Moreover, the "Basic Standard" is only a departmental regulation promulgated by the State Administration of Traditional Chinese Medicine. The hierarchy is not high and it is difficult to play a strong normative role.

\section{The Boundary Between Chinese Health Care Behaviors and TCM Diagnosis and Treatment Behaviors Is Blurry and There Is Over-range Management}

The "Basic Standards" pointed out that the projects that can be carried out by TCM health care service organizations include "consultation, guidance, massage, fumigation, 
moxibustion, sticking, cupping, scraping, and other various physical methods, natural remedies, etc. guided by theories and concepts of traditional Chinese medicine. "However, the division between TCM health care and TCM medical behavior is not clear, so that the supervision clause "not allowed to engage in medical activities" cannot play a substantial role. The expressions of "other physical methods and natural therapies guided by the theory and concepts of Chinese medicine" are relatively general and broad, and almost all nonchemotherapy can be attributed to them. "Prohibiting the use of methods or means that endanger human health and safety", then what methods and means are considered to be dangerous to human health and safety? Is hyperthermia such as moxibustion and cupping prohibited? Scrapping, orthopaedics, and massage manipulation are external forces regulating the skeletal muscles of the human skin. Improper handling can also cause local bleeding and redness. Is it necessary to stop it? Fumigation and sticking may also cause allergies to people with special physical constitutions. Does it also belong to the prohibition range? In the "Reply", the elimination method is further adopted to enumerate seven technical that non-medical institutions and their personnel who are not allowed to use in business activities such as acupuncture, scar moxibustion, foaming moxibustion, and traction and so on. Both the "Basic Standard" and "Reply" lack specific and clear reference standards, making it impossible to truly regulate the industry and the market.

Unclear boundaries and standards have caused TCM health care service organizations to start massages and scrapes in pedicure store, and beauty shops have developed "crossborder" businesses such as moxibustion, cupping, and physiotherapy in Chinese medicine. This phenomenon can be seen everywhere. Some even carry out medical activities that are of a therapeutic nature, which is an over-range business phenomenon. This not only seriously threatens the health and safety of the clients, but also causes health care accidents to occur frequently, resulting that "Chinese medicine" takes the blames innocently.

\section{The Management Subject Is Not Clear and the Supervision Is Absent}

At present, the vast majority of TCM health institutions are in the regulatory blind spot. Traditional Chinese medicine health care service involves many functional departments such as health, industry and commerce, taxation and so on. The health administrative department has no routine supervision over the non-medical organizations that carry out the health care projects of traditional Chinese medicine. If there is no complaint or report clue for suspected illegal medical practice, the health department has no right to conduct normal supervision of such institutions, but only does after investigation. Although the industrial and commercial department has the power to enforce and punish, it is unable to effectively supervise the management projects of the highly professional TCM health care services. Currently, this is an industry that seemingly anyone can manage, in fact, no one can really control. Only when related accidents occur, the Health Planning Commission, the Administration for Industry and Commerce, the Food and Drug Administration and other departments can initiate joint operations, but the multi-sector law enforcement mechanisms are not perfect, and coordination difficulties will arise, directly affecting the efficiency and effectiveness of the treatment.

\section{E. The Punishment of Illegal Acts Is Not Enough}

The TCM health service industry is a new industry. Any industry that is in its infancy will mean high returns. If illegal operations are carried out again, then it will definitely be able to earn huge profits. The TCM health care service is different from other service industries. Its service targets and service items provided have certain specialities, because its service behavior is directly related to the life and health of the service target.

As mentioned earlier, some Chinese health care institutions on the market are "hanging sheep heads and selling dog meat". Their registered business scope is not consistent with the actual business items, which brings great hidden danger to people's health and safety. Although the "Review" clearly defines the concept of "medical treatment activities in Chinese medicine" and lists the activities that non-medical organizations cannot engage in, it only stipulates "handling to agencies that have jurisdiction over the illegal activities". So which agencies have the jurisdictional authority? What are the treatment measures and how are they handled? None of these are further specified.

In reality, most of the illegal activities which do not cause harmful consequences are largely ignored. For unlawful acts that cause harmful consequences, it is stipulated that for lawbreakers with minor crime, according to the "Regulations on the Administration of Medical Institutions" or the "Implementing Details of the Regulations on the Administration of Medical Institutions", they shall be ordered to suspend their practice activities and be fined not more than 3,000 yuan or 10,000 yuan; for the law-breakers with heavier responsibility, the crime will be dealt with in accordance with the crime of illegal medical practice in the "Criminal Law", but the crime requires very serious circumstances and generally, the crime can be convicted and punished according to this provision is rarely. The above punishments and penalties are insignificant for the profitability of the health institutions that violate the law, and the low cost of the offense has prevented them from hurting the bones. After penalties have been imposed or business reorganization has been suspended, these institutions tend to change their looks and return again.

\section{THE WAY to SOlVE THE LEGAL Problems OF TCM HeAlTh CARE SERVICE}

\section{A. Establish a Complete Access System}

1) Establishment of registration and filing system: At present, the way of filing has been widely used in many administrative organs. In November 2017, the State Health Planning Commission issued the Interim Measures for the Record Management of Chinese Medicine Clinics, in which, the details of the record management of TCM clinics were clearly defined. The TCM health care services of non-medical institutions should also establish a registration and filing 
system as soon as possible. Under the precondition of preapproval of the competent department of the industry, they are required to apply to the industrial and commercial department for registration and filing. The main issues for registration and filing shall include the organization's name, personnel setting, business items, places and environment, facilities and equipment. When the major items of registration and registration are changed or they no longer engage in relevant business activities, they must go to the industrial and commercial department to make corresponding changes or cancel the record registration so as to facilitate the supervision and management of the industry.

In addition, TCM health care service providers should have a statutory place of practice and should be given special restrictions on their names, such as "XX TCM Health Care Club" and "Chinese Medicinal Health Care XX Club" to further improve the degree of standardization.

2) Introduction of technical norms and service standards as soon as possible: It is necessary to formulate scientific and reasonable technical norms and service standards as soon as possible to normatively position the service items, site environment, equipment and facilities, and personnel qualifications of TCM health care institutions. For example: to standardize each TCM health service project, stipulate which projects can only be carried out in the medical institutions, and non-medical institutions must not do it. For projects that can be carried out in medical institutions as well as in non-medical institutions, medical-grade standards and health care-grade standards should be established.

Specifically, the public health care services on the market mainly include massage, cupping, skin scraping, fumigation, moxibustion, acupoint application, food therapy, lavipeditum, cream, medicinal wine, body beautification. The author believes that the prescriptions for cream and medicinal wine should be carried out only in medical institutions while body beatification if it involves the minimally invasive techniques of traditional Chinese medicine can also only be carried out in medical institutions. In the final analysis, medicinal liquor and ointment are medicine, not ordinary tonic, nourishment. So, it is that not everyone can take them. They have their own suitable population, and there are also unsuitable people who must be careful and prohibited. The users must recognize their own conditions and physical condition, and it is advisable to use them under the guidance of Chinese medicine practitioners. Therefore, the two services of ointment and herbal medicine should also be appropriate in medical institutions. As for other services such as massage and scraping, both medical institutions and non-medical institutions all can be carried out, depending on the personal choices of consumers. However, non-medical organizations may not use medical terminology such as "Chinese medicine", "treatment" and disease names to promote, nor may they promote therapeutic effects.

3) Standardization of certification and settings of practitioner: Health care in TCM is an important activity that affects people's right to life and health. Therefore, the qualifications of relevant industry employees must have authoritative certification. Employees of TCM health service institutions must have the following qualification certificates: (1)the primary and above (including primary) professional certificate of TCM health care physician issued by the labor and social security department; (2)qualified health certificate stamped with health training assessment.

With regard to the personnel setting within the organization, the practice of Beijing's Dongcheng District, the pilot area of the access system, can be learned and classify the TCM health institutions in the local area into three levels. The settings and qualifications of practitioners in each class should be different. This practitioners' setup and qualification requirements of multi-form and multi-level are currently the best choice.

\section{B. Improvement of the Responsibility Division of the} Supervisor

The TCM health care services are also dependent on the existence and development of TCM technology and TCM. The TCM administrations around the country are the administrative examination and approval authorities for TCM health care organizations. The pre-qualification review will be conducted by the administrative department of Chinese medicine and the administrative department of health, and the administrative department for industry and commerce shall carry out the registration work. In addition, it is necessary to clarify the responsibilities of the various regulatory agencies, take the method of subsection supervision to establish a supervision linkage mechanism as soon as possible.

\section{Perfect the System of Legal Liability}

1) Perfect the administrative accountability system of the supervision department: The supervisory department shall bear the corresponding legal responsibility for actions that they have failed to or failed to correctly perform statutory duties due to intentional or negligent moves and caused damaged consequences. At present, it is imperative to formulate a set of administrative regulations to standardize and institutionalize administrative accountability. The design of legal norms can be specifically considered in terms of accountability subject, accountability cause, and accountability procedures. Only in this way can we avoid unlawful enforcement, lax enforcement, and profit-making to promote the healthy and orderly development of TCM health care service industry.

2) Increase penalties for illegal activities: The "Chinese Medicine Law" stipulates that "the competent department of Chinese medicine of the State Council shall formulate the norms and standards for the health care services of the TCM."It can be seen that the TCM health care behavior will have laws to follow, and people's life and health will also receive stronger protection. Specifically speaking, it is necessary to increase penalties for increasing illegal activities, increase the cost of illegal activities to reduce the probability of illegal activities. Once illegal activities such as overreaching operations and illegal medical practices are discovered, illegal institutions or enterprises must be ordered to suspend production and business operations, and no longer 
be allowed to engage in related industries. They may be punished with tens or even hundreds of times of the illegal proceeds.

\section{Promote Industry Associations to Participate in} Supervision and Management

In addition to strengthening the strict supervision of functional departments, TCM health care services can also attract the participation of social intermediary organizations. TCM health care service industry associations should be encouraged to participate in the supervision and management of the industry. Some of the regulatory functions may be transferred to industry associations and the associations can be commissioned to participate in the formulation of entry standards, personnel, technical standards, and regulatory methods. Industry associations and functional departments have a two-pronged approach, which is effectively guarantee the implementation of supervision work. Of course, industry associations still play a very limited role in the market supervision because of inadequate strength, so that they must also be further authorized by the law and effective support.

\section{CONCLUSION}

Although China's TCM healthcare industry has shown a vigorous development trend, it is still in its infancy and there are many problems. For example, relevant laws and regulations are not perfect, the strength of supervision is weak, the means are lacking, and citizens' physical and mental health is not guaranteed. It is imminent to speed up the formulation of TCM health care service standards, strictly control access system, strengthen supervision, and further regulate service.

\section{REFERENCES}

[1] Lingjuan $\mathrm{Hu}$, Ruifeng Li. "TCM Health Care Market Problems and Regulatory Models" [N].Chinese Medicine Guides,2014-10-25

[2] Jiebing Jiang. "Do Not Allow Chinese Medicine to be Amulet of Health Care Institutions" [N].China News of Traditional Chinese Medicine, 2017-6-5.

[3] Yong Cheng, Yun Shi, Yiming Cai.” Discussion on the Development of Health Care Service in Traditional Chinese Medicine” [J].Chinese Journal of Management in Chinese Medicine, 2011, 19. 